Article

\title{
Orange peel-based adsorbent for the removal of C.I. Disperse Blue 56 from textile
}

\section{dye industry effluents}

\author{
Nadia Torres ${ }^{1,2}$, Josep García-Raurich ${ }^{2}$, José M. Canal ${ }^{1}$ and Marta Riba-Moliner ${ }^{1, *}$ \\ 1 Universitat Politècnica de Catalunya (ETSEIAAT). c/ Colom 1, 08222 Terrassa (Spain) \\ 2 CRESCA, Universitat Politècnica de Catalunya (ESEIAAT). c/ Colom 1, 08222 Terrassa (Spain) \\ * Correspondence: marta.riba@upc.edu
}

Citation: Lastname, F.; Lastname, F.; Lastname, F. Title. Appl. Sci. 2021, 11, x. https://doi.org/10.3390/xxxxx

Academic Editor: Firstname Lastname

\begin{abstract}
This study demonstrates the viability of an orange peel-based adsorbent as sustainable alternative for the elimination of the disperse dye C.I. Disperse Blue 56 present in waste waters of the dyeing industry of textiles. The effectiveness of the adsorbent is evaluated at different $\mathrm{pH}$ values and the adsorption capacity is determined by systematically comparing orange peel and the final adsorbent chemically treated. Results reveal an spontaneous coagulation-flocculation phenomenon of the dispersed dye at low $\mathrm{pH}$ values which represents a sustainable way for the recovery and possible re-use of the dye, together with the industrial valorisation of a wasting product as is orange peel.
\end{abstract}

Keywords: dye recovery; textile industry; effluents; sustainability; adsorbent; orange peel

\section{Introduction}

Wet chemical textile industry consumes large amounts of water, mainly in both, preparation and finishing operations. Thus, a vast generation of waste water containing dye remains, high and low biodegradable organic contaminants, matter in suspension, surfactants, salts and chlorinated compounds. Consequently, the necessity of primary, secondary and advanced treatments are mandatory in textile sector towards the elimination of organic matter, solids previously not removed and colour.

Because the majority of cases the production is discontinuous, a high variability in quantity and nature in the contamination of generated waste water occur. In this way, the difficulty to treat those effluents is relevant. Apart from important fluctuations, textile industry waste water is commonly characterized by parameters such as chemical oxygen demand (COD), biological oxygen demand (BOD), $\mathrm{pH}$, colour and salinity [1].

Dyes are highly visible even at low concentrations, however depending on the process and the current legislation their presence must be reduced down to $98 \%$ of concentration in the industrial effluent. Nevertheless, from 20 to $50 \%$ of the products is estimated to be evacuated in water in form of persistent contaminants not removable by conventional treatments. For this reason, a strong demand of technologies capable to eliminate colour and, consequently achieve recycle/re-use the large amount of water consumed in processes is becoming mandatory.

On the other hand, polyester (PES) fibres are the most consumed synthetic fibres in the world and so, collateral products as well. The main drawback of PES and its derivatives is that cannot be dyed with common dyes, consequently, the family of disperse dyes appeared in the market for that purpose. Disperse dyes are insoluble in water and are usually presented in form of aqueous dispersions of fine organic compounds. Dye fixation mechanism to fibre can be driven by physical or Van der Waals forces at moderate-high temperature. Dye auxiliaries, such as dispersing agents, are necessary to ensure the stability of the dispersion during dye process. Not absorbed products by PES after dye process are remaining in residual dye baths, increasing COD and BOD values of waste water. 
Currently, advanced oxidation and mineralization systems, together with electrocoagulation are the more conventional treatments for the total or partial removal of pigments and dyes from aqueous effluents[2-5]. Nevertheless, those technologies generally produce large volumes of sludge and are needed of the implementation of photocatalytic reactors and/or ultrasonic technology towards the reduction of it[6]. Alternatively, biological processes have been considered as effective paths for the treatment of coloured effluents, however important time restrictions have been revealed[7-9].

Forefront research lines are focused on the production of new low-cost adsorbing materials. For example, different activated charcoals from coconut husks or olive stones, among other residues[10-13]. Moreover, agro-industrial leftovers without any treatment such as rice husk, orange peel and cork slices have been also considered as low-cost adsorbents[14-16]. In this way, the valorisation of vegetal remnants for that purpose is attracting interest from the economic environmental point of views.

Here, a novel adsorbent based on orange peel with the objective to remove disperse dyes of textile industry effluents is presented. The procedure of obtaining the adsorbent from the peel is driven by easy and low-cost chemical treatments. The capacity to adsorb disperse dyes is evaluated at different $\mathrm{pH}$ values to simulate the high variability of industrial waste waters. Orange peel-based adsorbent is revealed as a promising alternative for the elimination of disperse dyes of textile effluents.

\section{Materials and Methods}

\section{Materials}

Commercial oranges were purchased in local commerce. Disperse dye C.I. Disperse blue $56 \mathrm{C}_{15} \mathrm{H}_{13} \mathrm{BrN}_{2} \mathrm{O}_{4}, \mathrm{Mw}=365.18 \mathrm{~g} / \mathrm{mol}$ (CAS Number 12217-79-7) was supplied by Yorkshire. Hydrochloric acid, calcium hydroxide and EDTA were purchased to Panreac. Copper (II) sulphate pentahydrate was supplied by Honeywell.

\section{Instruments}

A FB 15054 sonicator device from Fisherbrand was used at a working frequency of $37 \mathrm{kHz}$. FTIR and atomic absorption spectrophotometers were a Paragoni 500 and a AA6300 from Perkin Elmer and Shimadzu, respectively. UV-visible absorption spectroscopy was analyzed with a Shimadzu UV-1800 device. To measure the turbidity, a turbidimeter HI 88713-ISO was used.

\section{Orange peel preparation}

Endocarp is separated from the orange peel, leaving the flavedo and albedo clean. Peels without pulp were washed with water and anionic surfactant for $30 \mathrm{~min}$ to eliminate superficial applied waxes and resins and then, were dried under air flow at room temperature until constant weight. Afterwards, a mechanical milling followed by a sieving to obtain grain sizes of 200-500 $\mu \mathrm{m}$ and 500-1000 $\mu \mathrm{m}$ were carried out.

\section{Chemical treatment}

Acid treatment (acidification): $50 \mathrm{~g}$ of grainy orange peel were immersed into a solution containing $5 \mathrm{~mL}$ of $\mathrm{HCl}$ concentrated and $700 \mathrm{~mL}$ distilled water under sonication for $45 \mathrm{~min}$. Finally, peel is rinsed with water.

Alkaline treatment (alkalinisation): $50 \mathrm{~g}$ of acid treated sample was immersed in a solution of calcium hydroxide $\left(\mathrm{Ca}(\mathrm{OH})_{2}\right)$ following procedure described by Arjona et al.[17] under sonication for $45 \mathrm{~min}$. Then, the excess of $\mathrm{Ca}(\mathrm{II})$ was eliminated by washing with distilled water.

Final washing: several washing procedures of the adsorbent after chemical treatment were explored to find the optimal obtaining process conditions towards the production of an efficient adsorbent. Procedures are gathered in Table 1.

Table 1. Adsorbent washing procedures analyzed. 
3 washings with distilled water and sonication +6 washings with distilled water and

1 light stirring. 45 min each washing

2

Washings with distilled water and light stirring. 45 min each washing

Washings with a $0.005 \mathrm{M} \mathrm{EDTA}^{1}$ solution and light stirring. 1 min each washing

\footnotetext{
${ }^{1}$ to determine the correlation between number of washings and the amount of retained $\mathrm{Ca}(\mathrm{OH})_{2}$.
}

\section{Water absorption capacity determination}

The determination of the water absorption was conducted by adding a known volume of water to a known weight of peel/adsorbent under stirring for $5 \mathrm{~min}$. Then, the matter was filtered and the exceeding water was quantified.

\section{Absorption capacity determination}

The absorption capacity of the adsorbent was determined by atomic absorption spectroscopy. To do this, solutions of $30 \mathrm{ppm}$ copper (II) sulphate pentahydrate $\left(\mathrm{CuSO}_{4} \cdot 5 \mathrm{H}_{2} \mathrm{O}\right)$ were prepared. Chemically treated orange peel adsorbent was immersed in the solution under stirring for 30 minutes. On the other hand, aqueous solutions of $2 \mathrm{~g} / \mathrm{L}$ of disperse dye with Liogen DFTN $(1 \mathrm{~g} / \mathrm{L})$ were prepared as dyebath.

\section{Results}

\subsection{Effectiveness of the chemical treatment}

The first step was the preparation of the orange peel. Two ranges of grain sizes were obtained, 200-500 $\mu \mathrm{m}$ and 500-1000 $\mu \mathrm{m}$, in order to evaluate later the influence of the adsorbent size. Afterwards, peel grains were chemically treated with an acidic treatment towards the removal of pectins and other organic compounds from the orange (hemicellulose, reducing sugars and part of the flavonoids). Pectin extraction was a necessary step due two main reasons: (i) its capacity to form colloids and to absorb large amount of water and, (ii) to acquire a final product with a sufficient consistency to be used in a continuous process of discolouration. Conventional pectin removing processes are developed ca. $90^{\circ} \mathrm{C}$ for $1 \mathrm{~h}[18]$, however sonication technology was used here with the objective to execute a more efficient process[19].

Furthermore, remaining pectin in the grains was saponified and crosslinked in a single-step by alkaline treatment using $\mathrm{Ca}(\mathrm{OH})_{2}$. Resulting adsorbent was dried at $110^{\circ} \mathrm{C}$ and milled until obtain grain sizes between 200-500 $\mu \mathrm{m}$ and 500-1000 $\mu \mathrm{m}$. Chemical treatment was evaluated by infrared spectroscopy (FTIR) (Figure 1).

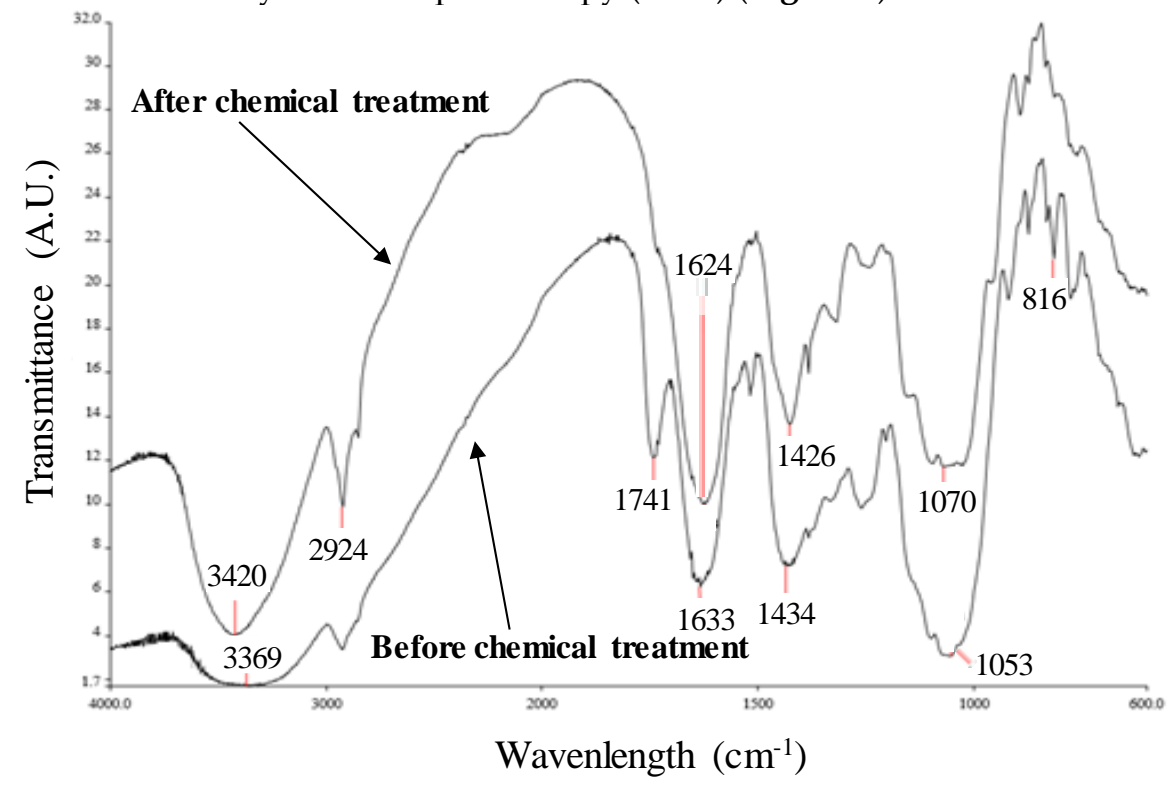


Figure 1 FTIR spectra of the adsorbent before and after chemical treatment.

\subsection{Physico-chemical properties of the adsorbent}

Firstly, in order to set the volume of water necessary in the chemical treatment steps, the capacity of water absorption of the orange peel was determined (Table 2).

Table 2. Water absorption of orange peels of different grain sizes.

\begin{tabular}{cccccc}
\hline & \multicolumn{2}{c}{$\mathbf{2 0 0 - 5 0 0 \mu m}$} & \multicolumn{2}{c}{$\mathbf{5 0 0 - 1 0 0 0} \boldsymbol{\mu m}$} \\
\hline Orange peel (g) $\begin{array}{c}\text { Initial water } \\
(\mathbf{m L})\end{array}$ & $\begin{array}{c}\text { Exceeding } \\
\text { water }(\mathbf{m L})\end{array}$ & $\begin{array}{c}\text { Absorbed } \\
\text { water }(\mathbf{m L} / \mathbf{g})\end{array}$ & $\begin{array}{c}\text { Exceeding } \\
\text { water }(\mathbf{m L})\end{array}$ & $\begin{array}{c}\text { Absorbed } \\
\text { water }(\mathbf{m L} / \mathbf{g})\end{array}$ \\
\hline 1 & 20 & 11.5 & $8.50 \pm 0.28$ & 11.8 & $8.20 \pm 1.1$ \\
\hline 3 & 40 & 15.0 & $8.33 \pm 0.28$ & 16.0 & $8.00 \pm 1.1$ \\
\hline 5 & 100 & 57.2 & $8.56 \pm 0.28$ & 11.0 & $7.80 \pm 1.1$ \\
\hline 10 & 100 & 14.7 & $8.53 \pm 0.28$ & 40.0 & $6.00 \pm 1.1$ \\
\hline 15 & 170 & 50.0 & $8.00 \pm 0.28$ & 80.0 & $6.00 \pm 1.1$ \\
\hline 20 & 200 & 37.0 & $8.15 \pm 0.28$ & 78.0 & $6.10 \pm 1.1$ \\
\hline
\end{tabular}

Due to the fact that some remaining organic fraction might be still present in the adsorbent according to FTIR results (see Discussion), the influence of an extra treatment with the incorporation of hydrogen peroxide $\left(\mathrm{H}_{2} \mathrm{O}_{2}\right)(0.4 \mathrm{M})$ as oxidizing agent during the acid treatment towards the exploration of the capacity of absorption of the adsorbent was conducted. Additionally, several number and types of washing procedures (see Materials and Methods) of the resulting adsorbents were tested. Then, the capacity of absorption of the adsorbent after the chemical treatment was indirectly evaluated through the measuring of the total content of $\mathrm{Cu}(\mathrm{II})$ absorbed as the result of the ionic interchange with $\mathrm{Ca}(\mathrm{II})$ by atomic absorption spectroscopy. Parameters such as grain size influence from the adsorbent before and after chemical treatment, the fact of the incorporation of $\mathrm{H}_{2} \mathrm{O}_{2}$ during acidic treatment and its volume, amount of $\mathrm{Ca}(\mathrm{OH})_{2}$ in the alkaline treatment and number and type of washings of the final adsorbent were analysed (Table 3).

On the other hand, Fehling assays were conducted to determine the presence of reducing sugars in the adsorbent on some of the samples (Figure 2).
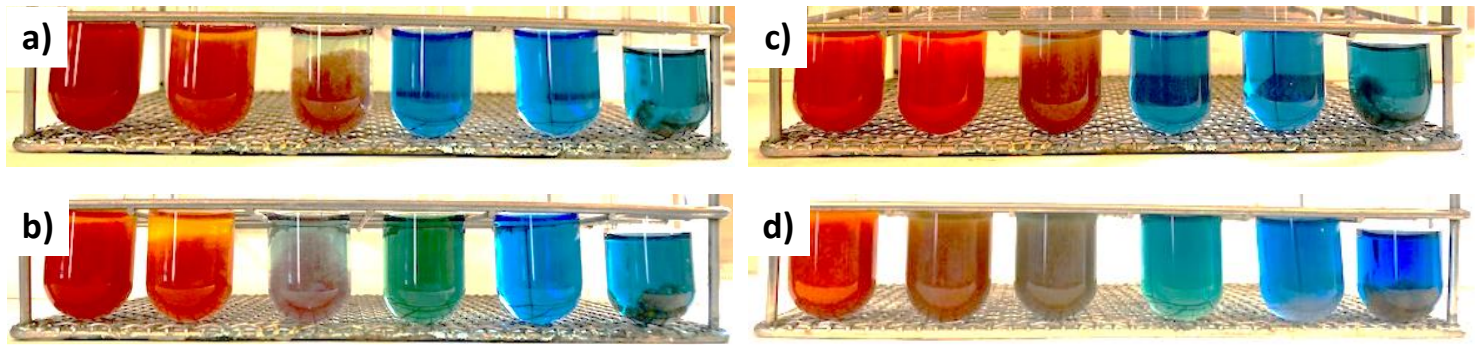

Figure 2 Fehling assay results of sample 1 a), sample 6 b), sample 7 c) and, sample 22 d). For each assay, 6 experiments were conducted on samples after the acid treatment, the addition of $\mathrm{H}_{2} \mathrm{O}_{2}$, the neutralization, the alkaline treatment, the final washing and on the final adsorbent.

Once the conditions were set (see Discussion), the adsorbency of the chemically treated adsorbent with those conditions towards the elimination of a disperse dye was carried out. In first term, the correlation between the behaviour of the coloured solution in contact with the adsorbent and $\mathrm{pH}$ was explored. To do this, the alkalinisation of solutions was conducted by two ways, one using $\mathrm{NaOH}(0.05 \mathrm{M} \mathrm{NaOH}$ in $25 \mathrm{~mL}$ of dye solution) and another using ammonia chloride/ammonia buffer solution ( $1 \mathrm{~mL}$ in $25 \mathrm{~mL}$ of dye solution). A viscous precipitated was observed when $\mathrm{pH}$ value was 10 using $\mathrm{NaOH}$ 
(Figure 3). Additionally, the supernatant liquid experienced an irreversible change from violet to brown colour, suggesting a possible degradation of the solution. Contrastingly, no precipitated and change of colour was spotted at same $\mathrm{pH}$ using buffered solution. Thus, the alkalinisation procedure using $\mathrm{NaOH}$ was discarded.

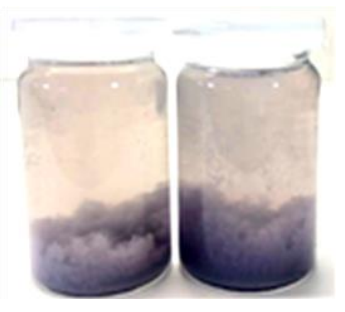

Figure 3 Viscous precipitated of dye solutions of (left) $0.012 \mathrm{~g} / \mathrm{l}$ and (right) $0.015 \mathrm{~g} / \mathrm{l}$ of dye respectively, after alkaline treatment using $\mathrm{NaOH}$.

Afterwards, the acidification of solutions was also developed by two methods, one using $\mathrm{H}_{2} \mathrm{SO}_{4}$ and another using acetic acid/sodium acetate buffered solution (50/50 wt). In the same way to alkalinisation the procedure, no precipitated and no change of colour could be observed at a $\mathrm{pH}$ value of 3.9 using acid buffered solution. This behaviour was found to be the same when the acidification was done with $\mathrm{H}_{2} \mathrm{SO}_{4}$ until $\mathrm{pH} \leq 2$. With this, a high variability on the aggregation behaviour of the dye depending on the $\mathrm{pH}$ value and the way of alkalinisation/acidification methodology could be concluded.

Due to the observed dependence of dye aggregation and $\mathrm{pH}$ values, the capacity of adsorption of the chemically treated adsorbent to the dye at different $\mathrm{pH}$ was explored. The $\mathrm{pH}$ values that were established to study were $\mathrm{pH}=4$ (using acetic acid/sodium acetate buffer solution), $\mathrm{pH}=6$ (own $\mathrm{pH}$ of dye solution) and $\mathrm{pH}=10$ (using ammonia chloride/ammonia buffer solution). To do this, $0.5 \mathrm{~g}$ of chemically treated adsorbent (previously hydrated for 24h) was put together with $25 \mathrm{~mL}$ of dye solution under smooth stirring for $30 \mathrm{~min}$. Then, the solution was filtered using a $0.45 \mu \mathrm{m}$ pore. Percentages of adsorbed dye through 200-500 $\mu \mathrm{m}$ and 500-1000 $\mu \mathrm{m}$ grain sizes of the chemically treated adsorbents were determined by UV-Vis absorption spectroscopy (Figure 4a and 4c). Furthermore, turbidity assays were conducted in order to see whether unpredictable spectroscopic results could be explained by the increase of the suspended solids (Figure $4 \mathbf{d}$ and 4d).

Table 3. Influence of the experimental conditions for obtaining the absorbent to the adsorption of $\mathrm{Cu}(\mathrm{II})$.

\begin{tabular}{|c|c|c|c|c|c|c|c|}
\hline Sample & $\begin{array}{c}\text { Grain size before } \\
\text { chemical treat. } \\
(\mu \mathrm{m})\end{array}$ & $\begin{array}{l}\mathrm{H}_{2} \mathrm{O}_{2} \\
(\mathrm{~mL})\end{array}$ & $\begin{array}{c}\mathrm{Ca}(\mathrm{OH})_{2} \\
(\mathrm{~g})\end{array}$ & $\begin{array}{l}\text { Washing } \\
\text { procedure }\end{array}$ & $\begin{array}{c}\text { № of } \\
\text { washings }\end{array}$ & $\begin{array}{c}\text { Grain size after } \\
\text { chemical treat. } \\
(\mu \mathrm{m})\end{array}$ & $\begin{array}{c}\mathrm{Cu}(\mathrm{II}) \text { adsorption } \\
(\%)\end{array}$ \\
\hline 1 & \multirow{3}{*}{$200-500$} & 5 & 5 & \multirow{7}{*}{1} & \multirow{7}{*}{-} & $200-500$ & 96.52 \\
\hline 2 & & \multirow{2}{*}{15} & 2.5 & & & $200-500$ & 98.28 \\
\hline 3 & & & 5 & & & $500-1000$ & 97.25 \\
\hline 4 & \multirow{4}{*}{$500-1000$} & \multirow{2}{*}{5} & 2.5 & & & $200-500$ & 98.18 \\
\hline 5 & & & 5 & & & $500-1000$ & 96.00 \\
\hline 6 & & \multirow{2}{*}{15} & 2.5 & & & $200-500$ & 98.62 \\
\hline 7 & & & 5 & & & $500-1000$ & 97.17 \\
\hline 8 & \multirow{3}{*}{$200-500$} & 5 & 2.5 & & 0 & $200-500$ & 92.13 \\
\hline 9 & & \multirow{2}{*}{15} & 2.5 & 2 & 0 & $500-1000$ & 92.05 \\
\hline 10 & & & 5 & & 11 & $200-500$ & 99.71 \\
\hline
\end{tabular}




\begin{tabular}{|c|c|c|c|c|c|c|c|}
\hline 11 & \multirow{4}{*}{ 500-1000 } & \multirow{2}{*}{5} & 2.5 & & 8 & 500-1000 & 97.98 \\
\hline 12 & & & 5 & & 11 & $200-500$ & 97.56 \\
\hline 13 & & \multirow{2}{*}{15} & 2.5 & & 8 & 500-1000 & 96.03 \\
\hline 14 & & & 5 & & 11 & $200-500$ & 97.97 \\
\hline 15 & \multirow{2}{*}{ 500-1000 } & 5 & 2.5 & & 8 & $500-1000$ & 97.36 \\
\hline 16 & & 15 & 5 & & 11 & $200-500$ & 98.45 \\
\hline 17 & \multirow{3}{*}{$200-500$} & 5 & 1 & & \multirow{3}{*}{5} & $500-1000$ & 97.74 \\
\hline 18 & & \multirow{2}{*}{15} & \multirow{2}{*}{1} & & & $200-500$ & 97.65 \\
\hline 19 & & & & & & $500-1000$ & 96.34 \\
\hline 20 & $200-500$ & \multirow{3}{*}{-} & 1 & & \multirow{2}{*}{5} & $200-500$ & 97.81 \\
\hline 21 & \multirow{2}{*}{ 500-1000 } & & 1 & 3 & & $500-1000$ & 96.77 \\
\hline 22 & & & 10 & & 7 & $200-500$ & 96.09 \\
\hline
\end{tabular}
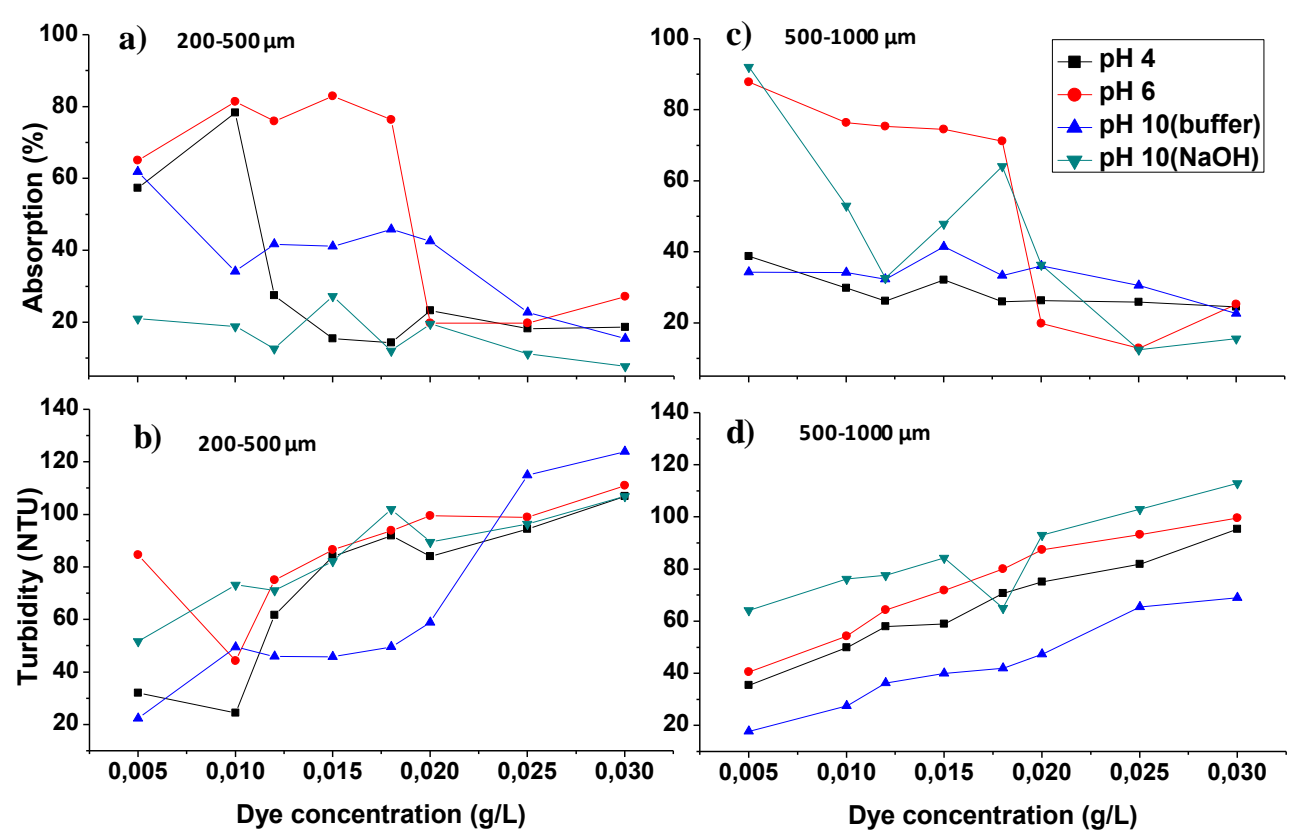

Figure 4 Absorption evolution a) and c) and turbidity b) and d) vs. dye concentration for chemically treated adsorbent grain sizes of 200-500 $\mu \mathrm{m}$ and of 500-1000 $\mu \mathrm{m}$, respectively.

Alternatively, same percentage absorption determination assays and turbidity measurements were conducted for non-chemically treated orange peel-based adsorbent with the objective to confirm those results (Figure 5). 

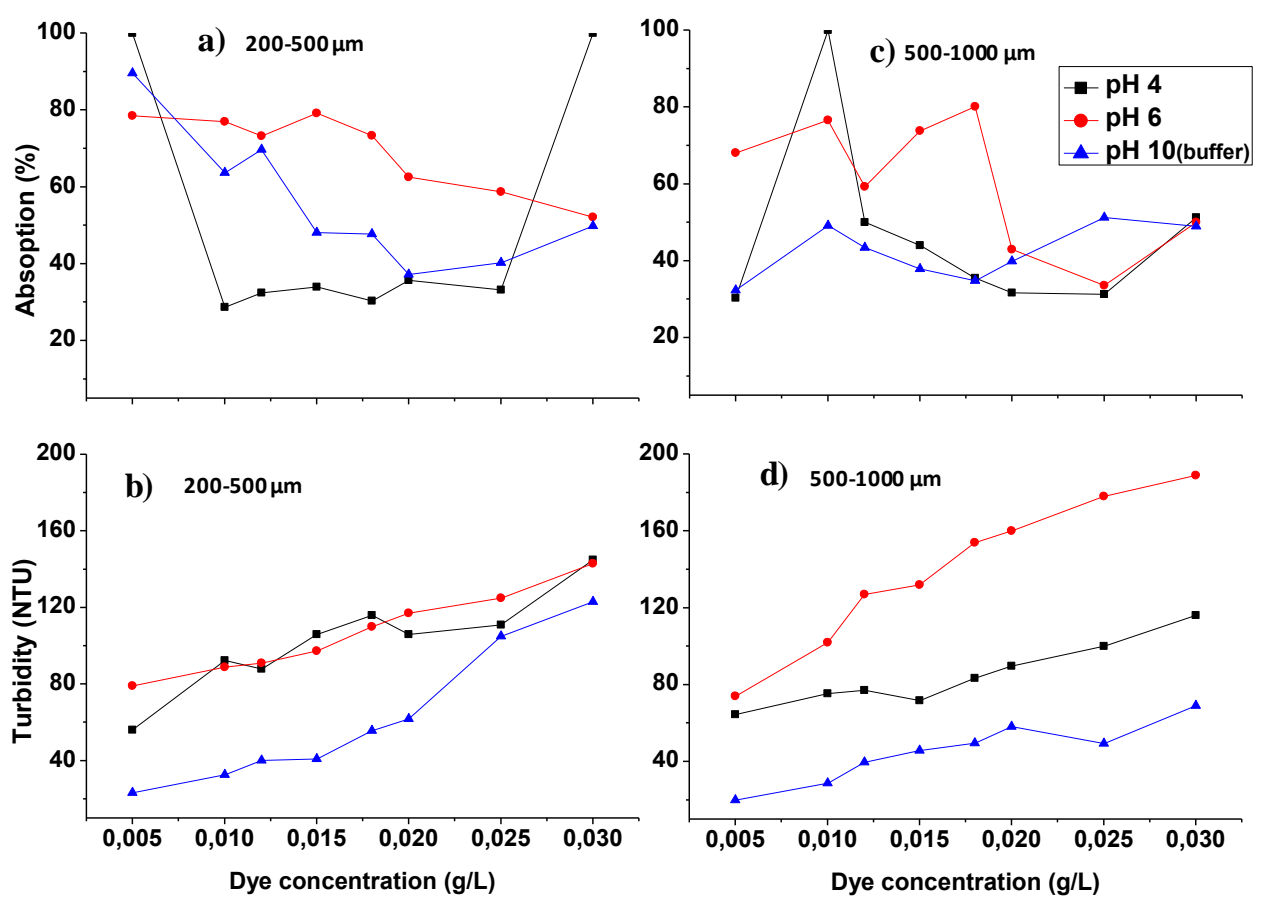

Figure 5 Absorption evolution a) and c) and turbidity b) and d) vs. dye concentration for nonchemically treated adsorbent grain sizes of $200-500 \mu \mathrm{m}$ and of $500-1000 \mu \mathrm{m}$, respectively. NOTE: $100 \%$ absorption values correspond to a spontaneous coagulation-flocculation phenomenon of the dye, for both grain sizes.

Concomitantly, a sporadic coagulation-flocculation phenomenon of the dye at a $\mathrm{pH}$ $=4$ could be observed when non-chemically treated adsorbent was used. For this reason, more detailed experiments were developed to determine $\mathrm{pH}$ influence on the adsorbency of the non-chemically treated adsorbent using solutions of $\mathrm{H}_{2} \mathrm{SO}_{4}(25 \%$ conc.) to reach $\mathrm{pH}$ values around 1 and 2. Results showed a total discoloration of the liquid phase and the formation of a solid phase at the bottom of the vessel, easily to separate by filtration (Figure 6). Even though the final liquid phase was colourless, the sedimentation rates were different according to $\mathrm{pH}$ values and grain size. Coagulation-flocculation rate process took $90 \mathrm{~min}$ for samples with $\mathrm{pH}$ values of 2.2 and an adsorbent grain size of 200-500 $\mu \mathrm{m}$, significantly slower than the observed for $\mathrm{pH}$ values below 2 (which took $300 \mathrm{~min}$ ). After several assays, conditions of coagulation-flocculation phenomenon could be determined, those being $0.5 \mathrm{~g}$ of non-chemically treated adsorbent $24 \mathrm{~h}$ hydrated previously in $25 \mathrm{~mL}$ of dyebath, under smooth stirring for $30 \mathrm{~min}$.

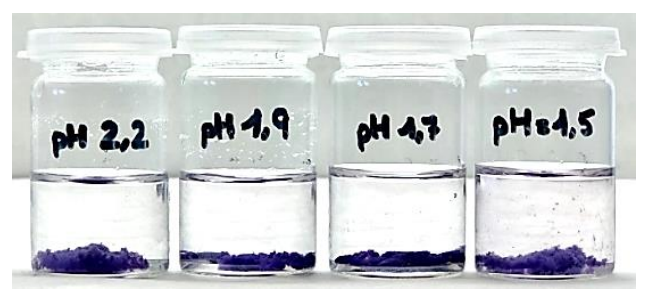

Figure 6 Dyebaths after addition of non-chemically treated orange peel-based adsorbent at different $\mathrm{pH}$ values of (left to right) 2.2, 1.9, 1.7 and 1.5.

Finally, pectins were extracted from the orange peel and, subsequently dried, milled and seized down to $200-500$ and $500-1000 \mu \mathrm{m}$ to determine their influence in the coagulation-flocculation phenomenon. Those pectins were mixed with the dyebath but no precipitated was formed.

\section{Discussion}




\subsection{Effectiveness of the chemical treatment}

FTIR demonstrated that the loss of the peak at $1741 \mathrm{~cm}^{-1}$ of the adsorbent after chemical treatment respect original sample was attributed to the elimination of high-methoxy pectins (Figure 1)[20]. Broad bands at 3600-3200 $\mathrm{cm}^{-1}$ centered at $3369 \mathrm{~cm}^{-1}$ for the peel before the treatment and at $3420 \mathrm{~cm}^{-1}$ for the absorbent were assigned to hydroxyl groups. Thus, cellulose, pectin, absorbed water, hemicellulose and lignin were assumed to be present in greater or lesser extent after the chemical treatment. The removal of hemicellulose could not be clearly appreciated due to cellulose is the main content of citric peels. Finally, peaks around $1430 \mathrm{~cm}^{-1}$ and $1060 \mathrm{~cm}^{-1}$ suggested the presence of $\mathrm{C}-\mathrm{H}$ aliphatic, aromatic, as well as $\mathrm{C}-\mathrm{O}$ carboxylic acid and ether groups, respectively[21].

\subsection{Physico-chemical properties of the adsorbent}

Water absorption results showed to be different for the diverse grain sizes (Table 2). A range of variability of $0.56 \mathrm{~mL} / \mathrm{g}$ was observed for grain sizes of $200-500 \mu \mathrm{m}$, independently of the quantity of orange peel and volume of water added. Contrastingly, a significant decreasing of the absorption was notified in samples 500-1000 $\mu \mathrm{m}$ for orange peel contents higher than $3 \mathrm{~g}$, probably due to the less specific surface of the sample respect to the other.

The adsorbency of the orange-based adsorbent on the $\mathrm{Cu}$ (II) elimination revealed to be very high for all samples, with a mean value of $97.04 \% \pm 3.83$, regardless of the concentration of $\mathrm{H}_{2} \mathrm{O}_{2}$ and $\mathrm{Ca}(\mathrm{OH})_{2}$, the number of washings and grain size (Table 3). Consequently, an adsorbent with ionic-exchange properties could be concluded. Due to these results, the treatment with $\mathrm{H}_{2} \mathrm{O}_{2}$ during acid treatment was forgotten and a concentration of $0.02 \mathrm{M} \mathrm{Ca}(\mathrm{OH})_{2}$ in the saponification process was established.

On the other hand, Fehling assays denoted a still high content of sugars after acidic treatment, even after the addition of $\mathrm{H}_{2} \mathrm{O}_{2}$ for all cases, according to the evolution of the colouring of the solutions (Figure 2). However, the alkaline treatment with $\mathrm{Ca}(\mathrm{OH})_{2}$ remarkably reduced the presence of reducing sugars until, finally, the absence of reducing sugars in the differently processed adsorbents could be concluded.

Additionally, UV-Vis absorption measurements of the coloured solutions (Figure 4a and $4 \mathrm{~b}$ ) denoted that no clear correlation could be established between the percentage of removed dye and initial concentration of dye. Even a decreasing of the absorption intensity was spotted at high dye concentrations in both samples. These observations were attributed to the presence of solids in suspension which were confirmed by turbidity assays (Figure $4 \mathrm{~d}$ and $4 \mathrm{~d}$ ). Turbidity results indicated an increasing tendency with the concentration of the dye for both grain sizes, corroborating the impossibility to stablish a correlation between absorption percentage and dye concentration by UV-Vis spectroscopy. Analogous results were obtained for non-chemically treated adsorbent being impossible to determine a correlation (Figure 5a and 5c). Nevertheless, results of turbidity allowed to establish a correlation between dye concentration and $\mathrm{pH}$ of the dyebath (Figure $\mathbf{5 b}$ and 5d). Higher values were observed when dye solution was set at $\mathrm{pH}$ value of 6 , concretely for grain sizes of $500-1000 \mu \mathrm{m}$, presumably pointing to an aggregation of the dye or a decrease of the dispersion stability of the dyebath.

Results of assays performed with non-chemically treated adsorbent at $\mathrm{pH}$ values around 1 and 2 showed the formation of a precipitated (Figure 6). This observation, together with the observation of non-precipitated formation when pectins of the adsorbent were extracted suggested that a formation of an insoluble complex pectin-dye was formed.

\section{Conclusions}

The effectiveness of a sustainable treatment to remove disperse dye $\mathrm{C}_{15} \mathrm{H}_{13} \mathrm{BrN}_{2} \mathrm{O}_{4}$ of textile dyeing effluents by the use of orange peel as natural adsorbent has been demonstrated. The behavior of the orange peel has been analyzed as adsorbent after washing, 
drying, milling and sieving and systematically compared before and after chemical treatment, resulting in adsorbents with grain sizes comprehended between 200-500 $\mu \mathrm{m}$ and 500-1000 $\mu \mathrm{m}$. Without chemical treatment, the orange peel has successfully removed the colour of dye solutions, observing more promising results with 500-1000 $\mu \mathrm{m}$ grain size and at a $\mathrm{pH}$ values between 1 and 2 .

Chemical treatment has consisted in an acidification process with $\mathrm{HCl}$ in order to eliminate soluble organic matter of the peel, followed by an alkaline process with $\mathrm{Ca}(\mathrm{OH})_{2}$ with the objective to saponify and cross-link the non-solubilized pectin fraction. Fehling assays has revealed an adsorbent free of reducing sugars and, after those treatments, more promising results have been obtained again with grain sizes of 500-1000 $\mu \mathrm{m}$ and pH values between 1 and 2 . In both conditions, a spontaneous process of coagulation-flocculation of the dye has been observed that has allowed the possibility to recover and potentially re-use the dye. The fastest sedimentation rate has been registered for the orange peel, without chemical treatment.

The process constitutes a significant advantage respect to the common used adsorbent-based processes because the raw material is prepared from agricultural waste and there is no need to be regenerated after use. These results open a real and sustainable alternative to classic colour-removal treatments of the waste waters and, additionally, open a new field of study regarding the behavior of the different disperse dyes (azoic and anthraquinonic-type) with the proposed adsorbent and their re-usability. Moreover, a prospective exploitation and valorisation of a by-product without economic value (orange peel) towards a new trade material can be implemented in future studies.

Author Contributions: Conceptualization, J.G.R., M.R.M. and J.M.C.; methodology, N.T.; validation, J.G.R., M.R.M. and J.M.C.; formal analysis, N.T.; investigation, J.G.R., M.R.M., J.M.C. and N.T.; resources, J.G.R., M.R.M. and J.M.C.; writing-original draft preparation, N.T. and M.R.M.; writing - review and editing, M.R.M.; visualization, M.R.M.; supervision, J.M.R., M.R.M. and J.M.C. All authors have read and agreed to the published version of the manuscript.

Funding: This research received no external funding.

Institutional Review Board Statement: Not applicable.

Informed Consent Statement: Not applicable.

Data Availability Statement: The data presented in this study are available on request from the corresponding author. The data are not publicly available due to intellectual property issues.

Conflicts of Interest: The authors declare no conflict of interest.

\section{References}

1. Yaseen, D.A.; Scholz, M. Textile Dye Wastewater Characteristics and Constituents of Synthetic Effluents: A Critical Review. Int. J. Environ. Sci. Technol. 2019, 16, 1193-1226, doi:10.1007/s13762-018-2130-z.

2. Buscio, V.; Marín, M.J.; Crespi, M.; Gutiérrez-Bouzán, C. Reuse of Textile Wastewater after Homogenization-Decantation Treatment Coupled to PVDF Ultrafiltration Membranes. Chem. Eng. J. 2015, 265, 122-128, doi:https://doi.org/10.1016/j.cej.2014.12.057.

3. Sen, S.; Pal, D.D.; Prajapati, A. Electrocoagulation Treatment of Textile Dyeing Effluent Using Aluminium Electrodes. In Proceedings of the International Conference on Recent Advances in Interdisciplinary Trends in Engineering \& Applications; April 92019.

4. Nidheesh, P. V; Zhou, M.; Oturan, M.A. An Overview on the Removal of Synthetic Dyes from Water by Electrochemical Advanced Oxidation Processes. Chemosphere 2018, 197, 210-227, doi:https://doi.org/10.1016/j.chemosphere.2017.12.195.

5. Bassyouni, D.G.; Hamad, H.A.; El-Ashtoukhy, E.-S.Z.; Amin, N.K.; El-Latif, M.M.A. Comparative Performance of Anodic Oxidation and Electrocoagulation as Clean Processes for Electrocatalytic Degradation of Diazo Dye Acid Brown 14 in Aqueous Medium. J. Hazard. Mater. 2017, 335, 178-187, doi:https://doi.org/10.1016/j.jhazmat.2017.04.045.

6. Moslehyani, A.; Hubadillah, S.K.; Dzarfan Othman, M.H.; Ismail, A.F.; Matsuura, T. Chapter 7 - PMRs in Photodegradation 
of Organic Contaminants: Water and Wastewater Treatment. In; Basile, A., Mozia, S., Molinari, R.B.T.-C.T. and F.D. on (Bio-) M., Eds.; Elsevier, 2018; pp. 189-208 ISBN 978-0-12-813549-5.

7. Sarvajith, M.; Reddy, G.K.K.; Nancharaiah, Y. V Textile Dye Biodecolourization and Ammonium Removal over Nitrite in Aerobic Granular Sludge Sequencing Batch Reactors. J. Hazard. Mater. 2018, 342, 536-543, doi:https://doi.org/10.1016/j.jhazmat.2017.08.064.

8. Khan, R.; Patel, V.; Khan, Z. Chapter 5 - Bioremediation of dyes from textile and dye manufacturing industry effluent. In; Singh, P., Kumar, A., Borthakur, A.B.T.-A. of E.P., Eds.; Elsevier, 2020; pp. 107-125 ISBN 978-0-12-818095-2.

9. Dayi, B.; Kyzy, A.D.; Abduloglu, Y.; Cikrikci, K.; Ardag Akdogan, H. Investigation of the Ability of Immobilized Cells to Different Carriers in Removal of Selected Dye and Characterization of Environmentally Friendly Laccase of Morchella Esculenta. Dye. Pigment. 2018, 151, 15-21, doi:https://doi.org/10.1016/j.dyepig.2017.12.038.

10. Lefebvre, L.; Agusti, G.; Bouzeggane, A.; Edouard, D. Adsorption of Dye with Carbon Media Supported on Polyurethane Open Cell Foam. Catal. Today 2018, 301, 98-103, doi:https://doi.org/10.1016/j.cattod.2017.05.025.

11. Lin, Y.; Ma, J.; Liu, W.; Li, Z.; He, K. Efficient Removal of Dyes from Dyeing Wastewater by Powder Activated Charcoal/Titanate Nanotube Nanocomposites: Adsorption and Photoregeneration. Environ. Sci. Pollut. Res. 2019, 26, 1026310273, doi:10.1007/s11356-019-04218-x.

12. Azaman, S.A.; Afandi, A.; Hameed, B.; Mohd Din, A.T. Removal of Malachite Green from Aqueous Phase Using Coconut Shell Activated Carbon: Adsorption, Desorption, and Reusability Studies. J. Appl. Sci. Eng. 2018, 21, 317-330, doi:10.6180/jase.201809_21(3).0003.

13. Benderdouche, N.; Benallou Benzekri, M.; Bestani, B.; Douara, N.; Duclaux, L. Valorization of Olive Stones into a Granular Activated Carbon for the Removal of Methylene Blue in Batch and Fixed Bed Modes. 2018.

14. Rachna, K.; Agarwal, A.; Singh, N.B. Rice Husk and Sodium Hydroxide Activated Rice Husk for Removal of Reactive Yellow Dye from Water. Mater. Today Proc. 2019, 12, 573-580, doi:https://doi.org/10.1016/j.matpr.2019.03.100.

15. Khasri, A.; Jamir, M.R.M.; Ahmad, M.A. Adsorbent from Orange Peel for Remazol Brilliant Dye Removal: Equilibrium and Kinetic Studies. AIP Conf. Proc. 2019, 2124, 20055, doi:10.1063/1.5117115.

16. Novais, R.M.; Caetano, A.P.F.; Seabra, M.P.; Labrincha, J.A.; Pullar, R.C. Extremely Fast and Efficient Methylene Blue Adsorption Using Eco-Friendly Cork and Paper Waste-Based Activated Carbon Adsorbents. J. Clean. Prod. 2018, 197, 11371147, doi:https://doi.org/10.1016/j.jclepro.2018.06.278.

17. Arjona, A.; Canal, J.M.; García Raurich, J. A New Biosorbent with Controlled Grain (I). Efficient Elimination of Cationic Dyes from Textile Dyeing Wastewater. IJOEAR 2018, 4, 14-27.

18. Fishman, M.L.; Cooke, P.H. The Structure of High-Methoxyl Sugar Acid Gels of Citrus Pectin as Determined by AFM. Carbohydr. Res. 2009, 344, 1792-1797, doi:https://doi.org/10.1016/j.carres.2008.09.031.

19. Freitas de Oliveira, C.; Giordani, D.; Lutckemier, R.; Gurak, P.D.; Cladera-Olivera, F.; Ferreira Marczak, L.D. Extraction of Pectin from Passion Fruit Peel Assisted by Ultrasound. LWT - Food Sci. Technol. 2016, 71, 110-115, doi:https://doi.org/10.1016/j.lwt.2016.03.027.

20. García, J.; Vázquez, A.; Pallarès, M.; Monagas, P.; Almajano, M.P. Application of Citrus Bioadsorbents as Wine Clarifiers. IJOEAR 2019, 5, 1-11.

21. Roldán, T.M.; Raurich, J.G. Biosorció de Coure Amb Pells de Cítrics En Procés Discontinu i En Procés Continu, Universitat Politècnica de Catalunya, 2019. 